\title{
Recent investigations of shock wave effects and interactions
}

\author{
P. M. Ligrani ${ }^{1,2^{*}}$, E. S. McNabb ${ }^{1,2}$, H. Collopy ${ }^{1,2}$, M. Anderson ${ }^{1,2}$ and S. M. Marko ${ }^{1,2}$
}

\author{
* Correspondence: pml0006@uah. \\ edu \\ ${ }^{1}$ Propulsion Research Center, \\ Department of Mechanical and \\ Aerospace Engineering, Olin B. King \\ Technology Hall S236, 5000 \\ Technology Drive, Huntsville, USA \\ ${ }^{2}$ University of Alabama in Huntsville, \\ Huntsville, AL 35899, USA
}

\begin{abstract}
Despite over fifty years of research on shock wave boundary layer effects and interactions, many related technical issues continue to be controversial and debated. The present survey provides an overview of the present state of knowledge on such effects and interactions, including discussions of: (i) general features of shock wave interactions, (ii) test section configurations for investigation of shock wave boundary layer interactions, (iii) origins and sources of unsteadiness associated with the interaction region, (iv) interactions which included thermal transport and convective heat transfer, and (v) shock wave interaction control investigations. Of particular interest are origins and sources of low-frequency, large-scale shock wave unsteadiness, flow physics of shock wave boundary layer interactions, and overall structure of different types of interactions. Information is also provided in regard to shock wave investigations, where heat transfer and thermal transport were important. Also considered are investigations of shock wave interaction control strategies, which overall, indicate that no single shock wave control strategy is available, which may be successfully applied to different shock wave arrangements, over a wide range of Mach numbers. Overall, the survey highlights the need for additional understanding of fundamental transport mechanisms, as related to shock waves, which are applicable to turbomachinery, aerospace, and aeronautical academic disciplines.
\end{abstract}

Keywords: Shock wave, Supersonic flow, Unsteady flow, Supersonic test sections, Thermal transport, Heat transfer, Shock wave control

\section{Introduction and background}

Shock waves are present in a variety of engineering application environments, such as transonic gas turbine blade tip gaps, transonic turbine blade passages, scramjet isolator ducts, supersonic aircraft engine intakes, adjacent to transonic and supersonic flight vehicle surfaces, and nearby surfaces of rockets, missiles, and reentry vehicles. These different application environments require consideration of the orientation, position, strength, and unsteadiness of the associated shock waves. The interactions between such shock waves and the boundary layers of these devices are of particular interest. This is because such interactions affect time- and spatially-varying static and stagnation pressure distributions, boundary layer development and separation, vortex formation, shear stress distributions, surface convective heat transfer, and flow transition stability. These, in turn, often affect engineering component performance characteristics, such as the presence and development of drag, including wave drag on external

(c) The Author(s). 2020 Open Access This article is distributed under the terms of the Creative Commons Attribution 4.0 International License (http://creativecommons.org/licenses/by/4.0/), which permits unrestricted use, distribution, and reproduction in any medium, provided you give appropriate credit to the original author(s) and the source, provide a link to the Creative Commons license, and indicate if changes were made. 
surfaces, unsteady buffet, aero-propulsion engine performance, and aero-propulsion engine efficiency. Shock wave control technologies are thus employed to reduce or minimize the adversarial effects of shock wave interactions as they affect such performance characteristics.

Currently active research areas include: (a) development of devices and technologies for implementation of specific control strategies, (b) determination of thermal transport and associated surface heat transfer effects, and (c) consideration of the origins and propagation of shock wave interaction unsteadiness. A significant number of investigations have been undertaken to consider this last area, and the consequent effects on nearby flow fields. Such studies have been especially beneficial as more complicated, three-dimensional flow fields are considered. Three typical shock wave configurations, which are often considered, include oblique shock waves caused by compression ramps, reflected oblique shock waves, and impinging normal shock waves. These different configurations can be generated in a constant-area duct, a diverging nozzle, or a multiple passage test section. Associated fundamental research is undertaken using either an experimental approach or a numerical approach. With the former, specially-designed test sections within wind tunnels are employed.

The unsteadiness that is associated with shock waves is either inherent, or is associated with flow phenomena which are present in other parts of the flow field. Because understanding and separating the relative effects and influences of these different unsteadiness origins are challenging tasks, origins and frequencies of the unsteadiness are debated. Frequency has been often represented by Strouhal number, which is advantageous because it can be representative of different flow conditions. In external flows with ramp-induced shock wave boundary layer interactions, Dussauge and Piponniau [1] concluded that the interaction unsteadiness occurred at Strouhal numbers between 0.02 and 0.05. Gonsalez and Dolling [2] and Clemens and Narayanaswamy [3] indicated that the Strouhal number of compression ramp unsteadiness ranged from 0.01 to 0.03 , where frequency was scaled based on the intermittent region length and the incoming velocity. These investigators reached this conclusion by considering boundary layer interactions with shock waves which were produced by blunt fins, sharp fins, as well as ramps. For the associated comparisons, the extent of this intermittent region corresponded to surface locations beneath the back and forth oscillatory motion of the separation shock wave. The success of these frequency scaling relationships evidenced similar physics for both weak and strong interactions.

Grilli et al. [4] also investigated very-low frequency motions near the foot of a shock wave produced by a compression-expansion ramp. These investigators indicated that frequencies associated with shock wave motions were two or three orders of magnitude smaller than frequencies associated with the incoming boundary layer, a conclusion in agreement with Dolling and Murphy [5] as well as with results from other investigators. However, despite these commonalities and agreements, scaling arrangements for other modes of unsteadiness associated with shock wave interactions (giving normalized frequencies which converge to single values) continue to be an important subject of investigation, especially for flows associated with impinging normal shock waves.

Some researchers, such as Humble et al. [6] and Ganapathisubramani et al. [7, 8], detected significant coherence between the upstream boundary layer and the unsteadiness in the shock wave interaction region. Others, such as Piponniau et al. [9] and Grilli 
et al. [4], did not emphasize significant correlation between the upstream boundary layer and the interaction region. Touber and Sandham [10] indicated that lowfrequency interaction region unsteadiness was not a result of forcing, either from the upstream or downstream boundary layer, but "an intrinsic property of the coupled system." These different perspectives may be a result of differences in interaction strength as described by Clemens and Narayanaswamy [3]. Interaction strength is directly related to the strength or relative size of separation, which is characterized by the magnitude of separated flow length scales. This strength also determines the degree to which an interaction exhibited sensitivity to upstream or downstream fluctuations. For flows with shock wave induced separation, other researchers, such as Piponniau et al. [9], Grilli et al. [4], Wu and Martín [11], and Pirozzoli et al. [12], indicated that unsteadiness in the interaction region was related to pulsations of the separation region. The causes of intrinsic separation bubble unsteadiness and reattachment point unsteadiness were believed to be either linked to the upstream boundary layer, as proposed by Pirozzoli et al. [12], or were the result of inherent dynamics between the separation bubble and the shock wave, as proposed by Piponniau et al. [9] and Grilli et al. [4].

Some reconciliation of these perspectives was provided by Clemens and Narayanaswamy [3], who indicated that both upstream and downstream mechanisms were present within all interactions, such that the degree of influence of the upstream boundary layer diminished as separation strength and scale increased. This means that the importance and effects of both mechanisms changed as separation strength varied. Thus, for some experimental conditions, the upstream boundary layer was an important source of disturbances, and shock wave unsteadiness was driven by fluctuations in the upstream boundary layer. Alternatively, shock wave unsteadiness was driven by some large-scale instability intrinsic to the separated flow, which were associated with the influences of downstream mechanisms on shock wave unsteadiness. Overall, Clemens and Narayanaswamy [3] indicated that the downstream mechanism dominated for strongly separated flows, and combined upstream and downstream mechanisms dominated for weakly separated flows. This diversity of perspectives, all from careful, meticulous, and skilled researchers, illustrates the challenges and difficulties in investigating shock wave effects and interactions.

The present survey considers these conflicting perspectives, as well as results from different investigations which appear to be consistent. The present survey is presented in five parts. Discussed first are general features of shock wave interactions. Discussed second are test section configurations for investigation of shock wave boundary layer interactions. Discussed third are the origins and sources of unsteadiness associated with the interaction region. Discussed fourth are interactions which included thermal transport and convective heat transfer. Presented last are shock wave interaction control investigations. The present survey is different from other recent shock wave review papers because of the information provided on the second, fourth, and fifth topics. The present review is also unique as updated perspectives are given in regard to the third topic.

\section{General features of shock wave interactions}

Figure 1, from Clemens and Narayanaswamy [3], shows overall flow features for three configurations, which result in different shock wave boundary layer interactions: (a) 


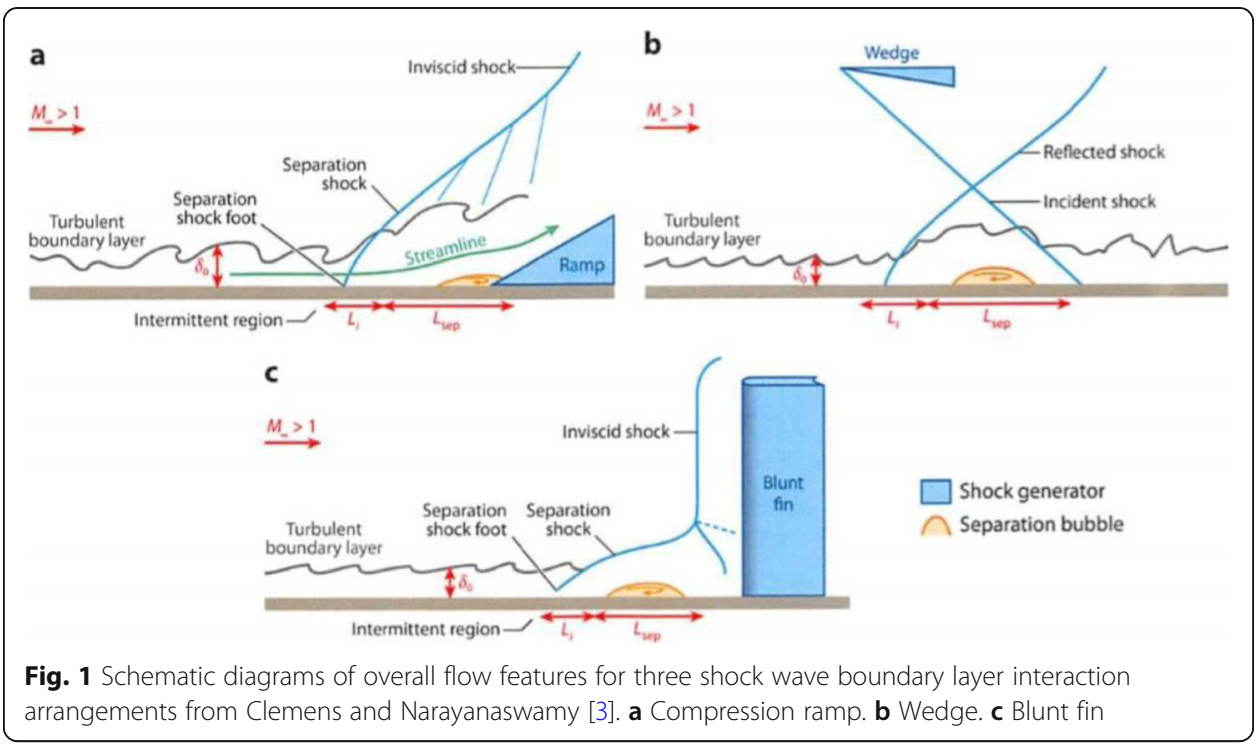

compression ramp, (b) wedge, and (c) blunt fin. Each of these results in different shock wave development and angles, as a consequence of different velocity and streamline variations relative to the imposed geometric boundaries.

Referring to Fig. 1a, with the ramp flow, the magnitude of separation depends on the ramp angle and the Reynolds number of the upstream boundary layer. This is because the Reynolds number is a measure of the ability of the boundary layer to resist separation. When the ramp angle is small, the adverse pressure gradient is not strong enough to separate the upstream boundary layer. As the ramp angle increases, a small separation bubble forms, and the oblique shock is then located upstream, relative to the ramp/surface corner. As the ramp angle increases further, the separation bubble increases in size, and the oblique shock wave is located progressively upstream. As the upstream boundary layer approaches the separation bubble, it separates from the wall, and then, advects over the bubble [3].

Note that qualitatively similar separation bubble flow arrangements are evident in Fig. $1 \mathrm{~b}$ and $\mathrm{c}$, for shock wave interaction flows resulting from the presence of the wedge and the blunt fin. The shock wave interaction flows near and adjacent to the compression ramp and the wedge are largely two-dimensional, whereas the interaction flows near the blunt fin are highly three-dimensional. All three arrangements produce separated regions, which recirculate upstream. According to Clemens and Narayanaswamy [3], such behavior characterizes separation interaction regions which are closed. Such closed regions sometimes show important physical similarities with open separated flows.

\section{Test section configurations for investigation of shock wave boundary layer interactions}

Three different topics are discussed within the present section: (i) upstream and downstream influences within diffuser flows, (ii) effects of imposed fluctuating downstream pressure, and (iii) use of dual passage test sections. As such, the present section provides information regarding experimental arrangements used to investigate shock wave 
phenomena, along with the resulting modes of flow unsteadiness associated with these arrangements.

\subsection{Upstream and downstream influences within diffuser flows}

Here, different diffuser configuration and flow parameters are related to shock wave interaction features, including frequencies of unsteadiness.

Sajben and Kroutil [13] determined the effects of the boundary layer thickness on shock wave unsteadiness. An experimental approach was employed wherein the position of a normal shock wave was tracked within a diffuser. Even without upstream or downstream forcing, shock wave oscillations were observed. According to these investigators, for shock wave boundary layer interactions without boundary layer separation, the thickness of the incoming boundary layer and the peak frequency of the shock wave motion were directly related. As such, peak frequency increased as boundary layer thickness increased. Bogar et al. [14] showed that, for cases where the boundary layer remains attached, the frequency of the shock wave motion depended inversely upon the length of diffuser duct. For the same configuration, Robinet and Casalis [15] numerically determined that the relationship between the diffuser length and shock wave oscillation frequency was caused by weak shock wave reflections at the diffuser exit. This conclusion was also verified by Handa et al. [16] using experimental and numerical techniques, who also attributed much shock wave motion to large pressure fluctuations, which appeared to originate at locations downstream of shock waves, where the flow was highly turbulent. Also observed were pressure fluctuations which originated near the shock wave foot. Sajben and Kroutil [13], Bogar et al. [14], and Robinet and Casalis [15] all indicated no correlation between shock wave frequencies and diffuser length when shock wave induced boundary layer separation was present.

\subsection{Effects of imposed fluctuating downstream pressure}

Edwards and Squire [17], Ott et al. [18], Bur et al. [19], Bruce and Babinsky [20], and Threadgill and Bruce [21] intentionally induced a pressure disturbance by rotating a cam in the flow downstream of the shock wave. Doerffer et al. [22] described a similar study wherein flow perturbations were induced by oscillating the angle of a choking flap. Sajben and Kroutil [13], Edwards and Squire [17], Ott et al. [18], Handa et al. [16], and Bur et al. [19] utilized experimental and numerical approaches to consider the effects of a variable-geometry second throat. With these approaches, shock wave boundary layer interaction response to a controlled, oscillatory, back pressure was addressed. Edwards and Squire [17] observed that the induced frequency was inversely proportional to the amplitude of the shock wave motion. Ott et al. [18] and Bur et al. [19] confirmed these observations, with agreement with Doerffer et al. [22] for excitation frequencies between $50 \mathrm{~Hz}$ and $512 \mathrm{~Hz}$. According to Doerffer et al. [22], for excitation frequencies below $50 \mathrm{~Hz}$, shock wave amplitude was constant because sufficient time was not provided to reach equilibrium pressures before reversal of the excitation occurred. Above $512 \mathrm{~Hz}$, the forced oscillations subsided and only natural oscillations were observed. Bruce and Babinsky [20] noted that the resonance in the wind tunnel greatly affected the data at certain excitation frequencies. Although there was not much variation in Mach number, these small changes greatly affected the interaction 
structure. This was because the shock-induced separation was very sensitive to changes in the shock strength at a specific Mach number.

\subsection{Use of dual passage test sections}

Bruce and Babinsky [20] indicated that controlling the position of a shock wave in a constant-area duct required great effort. Ogawa and Babinsky [23] stated that any shock wave control mechanism that reduces pressure losses increases shock wave instability. The shock wave motion direction was reversed when the stagnation pressure ratio (related to static pressure ratio) became too large or too small to sustain the shock wave position. This instability made shock wave control in conventional wind tunnels impossible. To address these issues, Ogawa and Babinsky [23] proposed a unique experimental arrangement to produce a normal shock wave, which impinged upon the boundary layer of a wind tunnel wall. This arrangement used a shock wave holding plate to partition the flow behind the shock wave into an upper, un-choked channel and a lower, choked channel. The arrangement had the benefit of producing a more stable shock wave than in a constant-area channel test section. The position of the shock wave holding plate, which separates the two channels, and the choking flap, which chokes the flow in the bottom channel, were manipulated to position the shock wave and produce desired testing conditions. A similar test section approach was employed by Ligrani and Marko [24]. Also see Marko and Ligrani [25].

\section{Origins and sources of unsteadiness associated with the interaction region}

Four different topics are discussed within the present section: (i) upstream forcing mechanisms, (ii) downstream forcing mechanisms, (iii) multiple forcing mechanisms, and (iv) side wall and corner effects. In general, considered are significant recent investigations, which address these subject areas.

\subsection{Upstream forcing mechanisms}

The results of Humble et al. [6] and Ganapathisubramani et al. [7, 8] indicated that large fluctuating structures in the upstream boundary layer were the cause of the shock wave boundary layer interaction unsteadiness for a range of experimental configurations. Both groups of investigators employed an arrangement wherein an incident oblique shock wave was generated from a shock generator with a $10^{\circ}$ angle at a flow Mach number of 2.1. Within the logarithmic region close to the wall, regions of high and low-speed flow were detected wherein a variety of structures were present. Included were long streamwise structures, referred to as hairpins, which were at least 2 boundary layer thicknesses in length. Ganapathisubramani et al. [7, 8] observations showed similar structures that were approximately 50 boundary layer thicknesses in extent in the streamwise direction and less than 0.5 boundary layer thicknesses in extent in the spanwise direction. According to Humble et al. [6], when large areas of high speed flow approached the shock wave, the reflected shock wave moved downstream. Conversely, as low-speed flow approached the interaction, the reflected shock wave was located farther upstream, relative to the interaction region. Ganapathisubramani et al. [7] suggested that the separation region, produced by the shock wave, responded to these upstream structures. 


\subsection{Downstream forcing mechanisms}

Piponniau et al. [9] concluded that shock wave motion was caused by the pulsating mass entrainment process of the separation region, instead of upstream forcing. Within shock wave boundary layer interactions in flows with reattaching separation regions, a forcing method was described which originated downstream. With this method, mass entered the separation region upstream and then exited downstream. Because the amount which exited was not the same as the amount which entered (since some of the flow was reversed), mass was accumulated within the separation region, which caused the separation region to increase in extent. This occurred until the mass in the separation region was significant enough to force a greater flow rate out, which was associated with an arrangement wherein the amount of mass exiting superseded the amount entering, which caused the separation region to shrink. Such cyclical growing and shrinking of the separation region caused a pulsation with the time scale which was related to the ratio of reverse flow mass to entrained flow mass. The investigators indicated that the reflected shock wave moved downstream as the separation region shrunk, and moved upstream as the separation region grew. Because the model developed by Piponniau et al. [9] provided scaling for unsteadiness frequencies over subsonic and supersonic Mach numbers, evidence was provided that associated separated flows were driven by an instability associated with entrainment of the separation bubble.

Grilli et al. [4] used large eddy simulations of supersonic turbulent boundary layers over a compression-expansion ramp, matching the experimental configuration employed by Zheltovodov et al. [26]. With this arrangement, the shock wave caused the boundary layer separation. Like Piponniau et al. [9], Grilli et al. [4] concluded that shock wave interaction unsteadiness was a consequence of the inherent dynamics between the separation bubble and the shock wave, and was not driven by upstream coherent structures. Separation region pulsations were caused by mass entrainment processes, which were associated with low-frequency motions associated with pulsations of the separation bubble. These then accompanied forward and backward motions of the shock wave. Shock wave unsteadiness was thus observed to come solely from separation region mass entrainment. Primary unsteadiness existed only in the region between the shock wave foot downstream to a location half-way through the separation region. As such, associated unsteadiness was not found to be prominent in the upstream boundary layer, nor was it present as the flow approached the reattachment point. Grilli et al. [4] also indicated that the structures considered by Ganapathisubramani et al. [7, 8] were outside of the experimental domain considered by their investigation.

\subsection{Multiple forcing mechanisms}

Wu and Martín [11] employed direct numerical simulations of a Mach 2.9 flow over a 24 degree compression ramp in order to detect and consider flow motions at different frequencies. These authors indicated that the true separation point and separation shock wave, at the edge of the boundary layer, oscillated together with highly correlated motion. The investigators also described significant correlation between fluctuations in the upstream boundary layer and separated flow motion, which was in agreement with measurements made by Ganapathisubramani et al. [7, 8] and Humble et al. [6]. 
Pirozzoli et al. [12] used large eddy simulations, with data mining, of reflected shock waves for different strengths of the incident shock waves. They observed that larger shock wave strength increased the size of the interaction zone, as a sizable separation bubble formed. High and low frequency modes of flow motion were investigated, where higher frequency activity was associated with turbulent structures, which were observed to propagate from the upstream boundary layer through the interaction region in the separated shear layer. For strong interactions with massive flow separation, lower frequency modes of motion were related to separation region pulses, which were three orders of magnitude smaller than the high frequency modes typical of boundary layer turbulence. The low-frequency motions associated with pulsations of the separation bubble were accompanied by fore-and-aft motion of the reflected shock wave. Magnitudes of dimensional low frequency near the interaction region were found to decrease as the separation region increased in size. The investigators indicated that the upstream boundary layer was supplying the low frequency energy to drive the pulsations of the separation region and shock wave.

Figure 2 from Pirozzoli et al. [12] shows filtered pressure fluctuation fields, with highpass and high-frequency data shown in frames a-b, and low-pass and low-frequency data shown in frames c-d. According to these investigators, the high-frequency part of the flow, shown in Fig. 2a and b, is prevalently associated with turbulence in the boundary layer and with the formation of local, vortical structures in the interaction region. The evolution of the pressure dips show that these structures propagate downstream of the shock wave. Turbulent structures are especially evident in the region of the separated shear layer. Figure $2 \mathrm{c}$ and $\mathrm{d}$ suggest that the low-frequency end of the flow spectrum is related to a breathing motion of expansion and compression of the separation bubble, which is coupled with upstream and downstream motions of the reflected shock wave.

Touber and Sandham [10] applied a numerical and an analytical model of an oblique impinging shock wave and its reflection within a Mach number 2.3, turbulent flow.

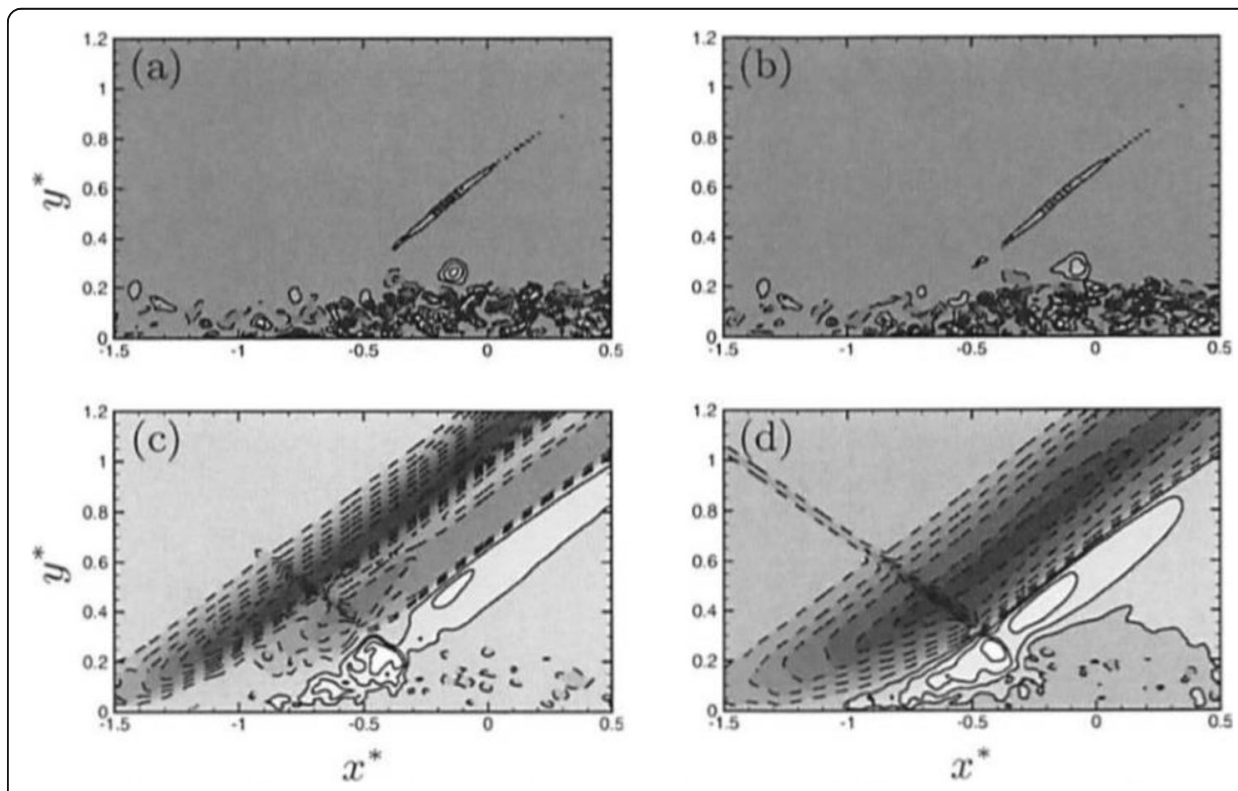

Fig. 2 Filtered pressure fluctuation fields. High-pass and high-frequency data (frames $\mathbf{a}-\mathbf{b}$ ) and low-pass and low-frequency data (frames c-d). Color scale from white (negative values) to black (positive values) [12]. 
Their model suggested that no significant low frequency structures, upstream nor downstream, were necessary to cause the shock wave boundary layer interaction unsteadiness. Instead, they supplied white noise fluctuations in the upstream boundary layer and discovered that the shock wave oscillations still occurred. They attributed the presence of particular unsteady frequencies to the low-pass filtering effect of the reflected shock wave boundary layer system.

Priebe and Martín [27] employed direct numerical simulations to investigate lowfrequency unsteadiness from shock wave-turbulent boundary layer interactions generated by a 24 degree compression ramp in Mach 2.9 flow. Consistent with experimental observations, the simulated shock waves experienced broadband streamwise oscillations at frequencies approximately two orders of magnitude lower than the characteristic frequency of the energetic turbulent scales in the incoming boundary layer. The authors indicated that the physical origin of the shock wave low-frequency unsteadiness was breathing of the separation bubble and flapping of the separated shear layer, especially as these phenomena were tied to the inherent instability in the downstream separated flow. Wu and Martín [11] and Priebe and Martín [27] also reported strong correlations between downstream flow fluctuations and separation shock wave motion. Wu and Martín [11] additionally showed a 30\% correlation coefficient between mass fluctuations in the upstream boundary layer and mass fluctuations associated with separation shock wave motion.

As discussed earlier, Clemens and Narayanaswamy [3] indicated that both upstream and downstream mechanisms were present within all interactions, such that the downstream mechanism dominated for strongly separated flows, and combined upstream and downstream mechanisms dominated for weakly separated flows. As such, the relative importance and effects of upstream and downstream mechanisms changed as separation strength varied. In particular, the degree of influence of the upstream boundary layer diminished as separation strength and scale increased. Thus, for weaker separations, the instability of the interaction system was not self-sustaining, but required an external driving source. As such, the upstream boundary layer was an important source of disturbances, and shock wave unsteadiness was driven by fluctuations in the upstream boundary layer. Turbulent fluctuations from upstream boundary layers were then generally correlated with separation bubble dynamics, with concomitant changes to the size of the separation bubble size or to the resulting shear layer with disturbances that result in large-scale flapping. With strongly separated flows, the forcing from the pulsating separation region dominated and masked the upstream component. In addition, shock wave unsteadiness was driven by large-scale instabilities associated with the separated flow, and the separated flow was driven by an instability associated with entrainment within the separation bubble. The separation bubble also pulsated in response to global instabilities that led to flapping of the reattachment point. The reattachment point fluctuations additionally caused expansion/contraction of the separation bubble and a synchronous movement of the separation line, separation shock (outside the boundary layer), and separation shock foot.

Illustration of correlation coefficient magnitudes associated with an interaction region and the downstream boundary layer are provided by the results shown in Fig. 3. These data were obtained at the University of Alabama in Huntsville using a newly operational transonic/supersonic wind tunnel system with a test section inlet Mach number of 1.54. 

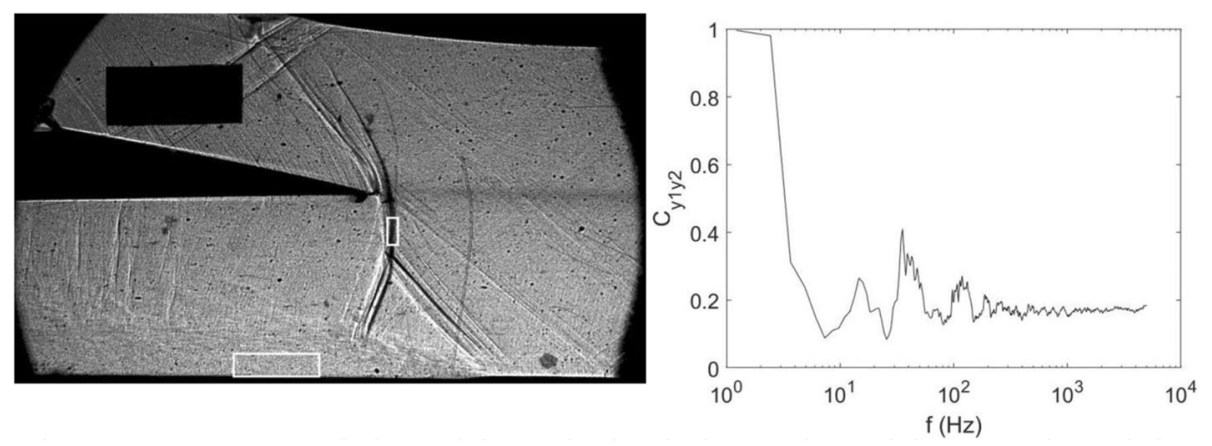

Fig. 3 a Instantaneous shadowgraph image showing shock wave characteristics. Rectangles mark the locations of the pixels in the downstream boundary layer and on the shock wave associated with magnitude squared coherence determination. $\mathbf{b}$ Magnitude squared coherence variation with frequency of data associated with locations near the shock wave and in the downstream boundary layer

Shown in Fig. 3a is an instantaneous shadowgraph image with flow direction from right to left. Present within the image are a well-defined normal shock wave, lambda foot, and separated turbulent boundary layer near the entrance of the lower flow passage. An oblique shock wave system is present near the entrance of and within the upper flow passage. The primary normal shock wave and associated lambda foot are evidenced by distinctly-defined individual lines within the Fig. 3a shadowgraph image, which evidence a largely two-dimensional flow field over the portion of the test section volume which is visualized using the shadowgraph system. The associated magnitude squared coherence variation with frequency of data associated with locations near the shock wave and in the downstream boundary layer are then presented in Fig. 3b. Associated data values evidence significant coherence between the shock wave and downstream boundary layer regions at frequencies of approximately $15 \mathrm{~Hz}, 30$ to $50 \mathrm{~Hz}$, and $100 \mathrm{~Hz}$, which correspond to Strouhal numbers (based upon intermittent region length) of approximately $0.004,0.008$ to 0.013 , and 0.026. Time lag values from grayscale flow visualization results indicate that perturbations of approximately $15 \mathrm{~Hz}$ and $100 \mathrm{~Hz}$ occur in the downstream boundary layer prior to the same frequency events in the shock wave. Data for events at frequencies at approximately $40 \mathrm{~Hz}$, indicate that the perturbations in the shock wave occur prior to the ones in the downstream boundary layer.

\subsection{Side wall and corner effects}

Burton and Babinsky [28] undertook experiments to examine the mechanisms behind the coupling between corner separation and separation away from the corner within a rectangular channel with a normal shock wave and a test section inlet Mach number of 1.5. The link between these different modes of separation was indicated to be related to the generation of compression waves at the corner, which acted to smear the adverse pressure gradient imposed upon other parts of the flow. These investigators indicated that corner separations altered the centerline flow in a significant fashion. For example, a reduction in corner separation resulted in increased centerline separation, whereas an increase in corner separation was connected to a smaller centerline separation. Additional corner effects were considered by Babinsky et al. [29], who addressed their influences on reflected oblique shock wave/boundary layer interactions. With a freestream 
Mach number of 2.5, the investigators showed that changing the size of the corner separations, through localized suction and small corner obstructions, altered the shape of the separated region in the central portions of the wind tunnel test section. Using numerical prediction tools, Wang et al. [30] considered side wall effects in regard to oblique shock wave/boundary layer interactions. Of particular interest were physical aspects of sidewall-induced three-dimensionality for moderately separated interactions at a Mach number of 2.7. As the wind tunnel aspect ratio decreased to unity, the separation and reattachment points on the central plane were observed to move upstream simultaneously, while the bubble length initially increased and then stabilized to a length which was $30 \%$ larger compared to the infinite-span, two-dimensional configuration. As such, three-dimensional flow structure was found to be induced by the swept interactions, which formed along the side walls of the test section.

\section{Interactions which included thermal transport and convective heat transfer}

Considered within this section are heat transfer and thermal transport shock wave investigations, as related to aerospace and aeronautical academic disciplines, and to turbomachinery academic disciplines. Review of the state of knowledge in this subject area is important because so little information is available in the archival literature, especially in regard to aerospace and aeronautical related research.

Investigations of heat transfer and thermal transport from shock wave interactions, as related to aerospace and aeronautical academic disciplines, were few in number and addressed only a limited range of experimental conditions. Some of the earliest aerospace shock wave heat transfer data were presented by Law [31] and by Christophel et al. [32] for a Mach number of 6, and by Oskam et al. [33] for a Mach number of 3. Holden [34] correlated results from swept interaction heat transfer experiments with the peak surface-pressure ratio, and showed that increased localized heat transfer occurs near the fin and surface intersection. Inger et al. [35] investigated the effects of heat transfer on shock/boundary layer interactions for a supercritical airfoil with minimal flow separations and a freestream Mach number of 1.3. It was found that increases in surface temperature of the airfoil led to significant increases in drag and decreases in lift, compared to subcritical airfoil performance with no shock waves present. According to these investigators, increases in boundary layer displacement thickness (and changes of boundary layer shape factor), due to increased wall temperature to adiabatic wall temperature ratio, were an important similitude parameter for airfoil and wing testing when viscous effects were present. It was also indicated that non-adiabatic wall temperatures may have even more significant influences for stronger shock waves, especially when buffet onset and lift are considered.

Neumann and Hayes [36] considered peak aerodynamic heating in sharp-fin-generated swept interactions, also indicating the presence of augmented local heat transfer distributions near the junction of the fin and the surface. Hayashi et al. [37] measured heat transfer distributions in swept interactions using thin- film gauges. In a later study, Hayashi et al. [38] described intense aerodynamic heating in the shockwave boundary layer interaction region for supersonic and hypersonic flows. Highly unsteady heat transfer rates were observed over very small length scales, which made them difficult to measure and quantify. With a freestream Mach number of 4, and a flat, aligned test plate, associated heat flux fluctuated over the entire interaction region when the boundary layer separated. 
With this arrangement, the largest fluctuations were measured near separation and reattachment regions, which were attributed to nearby shock wave unsteadiness. When no boundary layer separation was present, local surface heat flux variations became more pronounced near the impingement location of the incident shock wave. In another investigation, Rodi and Dolling [39] measured surface heat transfer variations from swept interactions at a Mach number of 5 using steady-state thermopile gauges.

Lee et al. [40] investigated shockwave/turbulent boundary layer interaction surface heat transfer, as produced by a swept fin configuration, angled at 10 to 20 degrees, relative to the mainstream flow direction. According to these investigators, local heat transfer and skin friction values were generally largest near reattachment locations, downstream of three-dimensional separation regions. Within these reattachment regions, continual increases of local surface Stanton number, with streamwise development, were observed. Peak heat transfer magnitudes were proportional to the interaction strength, as expressed by the Mach number normal to the swept shock wave. Inger [41] analyzed data measured for a compression ramp generated interaction region. Analytic models were provided for local variations of static pressure and surface heat transfer, as these are affected by the deflection angle of the ramp, for the incipient separation zone which was caused by the shock wave/boundary layer interaction.

With a free stream Mach number of 5, Schülein [42] considered two-dimensional interactions generated by oblique shock waves as they impinged onto a flat plate boundary layer, and three-dimensional interactions generated by a swept fin mounted within a flat plate boundary layer. Figure 4a from Schülein [42] shows the arrangement used

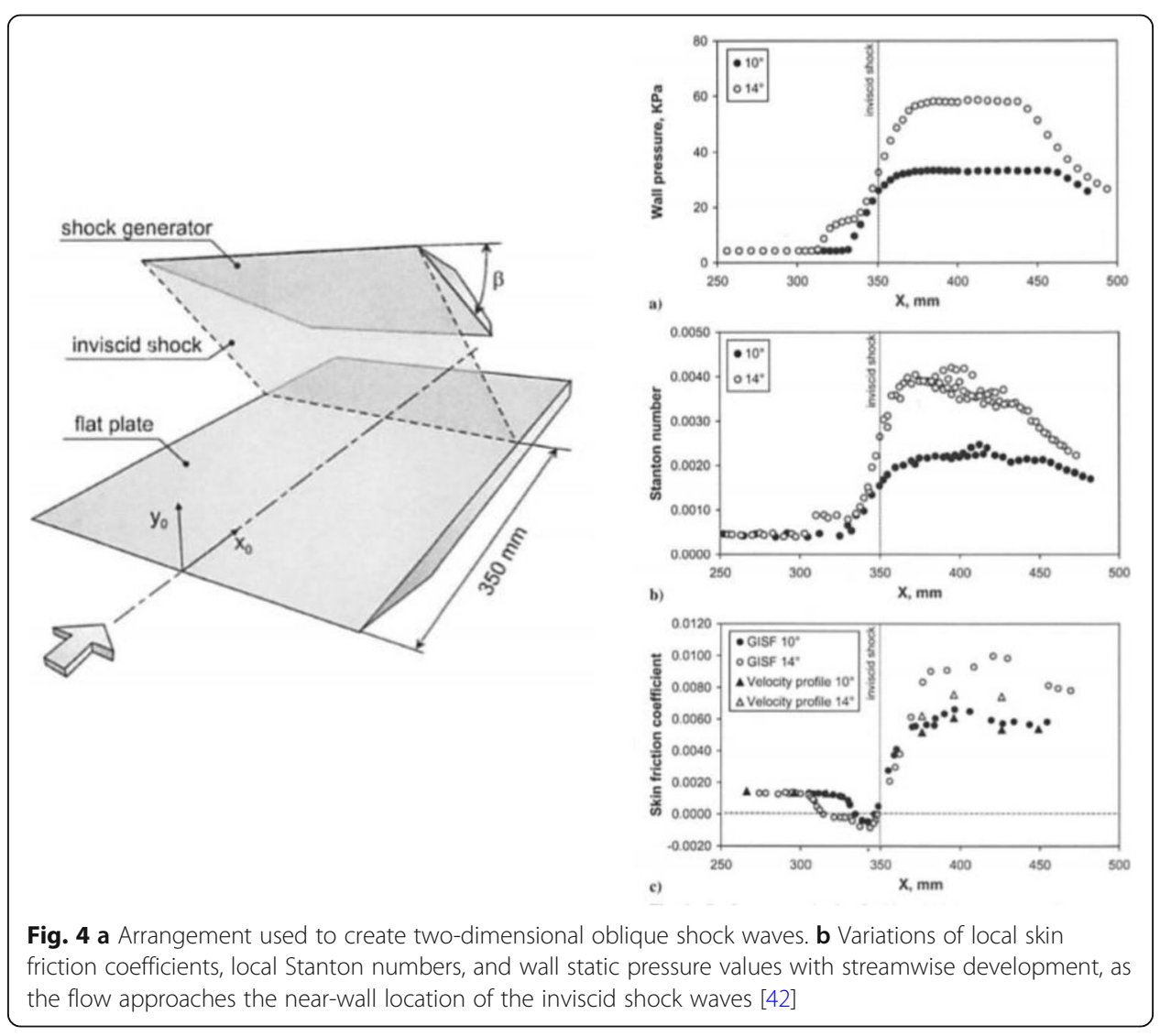


to create two-dimensional oblique shock waves. Examples of results are presented in Fig. 4b, where local skin friction coefficients initially decreased with streamwise development, as the flow approaches the near-wall location of the inviscid shock waves, whereas local Stanton numbers increased with streamwise development over the same streamwise locations. Figure 5a, also from Schülein [42], presents the arrangement used to create the swept fin, three-dimensional interactions. Within this three-dimensional arrangement, local skin friction and local surface heat transfer values increased locally in the vicinity of reattachment regions, and decreased locally near flow separation zones. Figure $5 \mathrm{~b}$ gives peak ratios of skin friction, heat flux, and wall static pressure as they varied with inviscid shock wave strength, for primary flow attachment line locations. Within this figure, all three ratios increased substantially as inviscid shock wave pressure ratio increased from 1 to 12 .

Song et al. [43] measured surface heat transfer distributions, which were associated with a sharp fin and a blunt fin. A freestream Mach number of 3 was employed, with results which showed that convective heat transfer gradually increased behind the primary separation line for both sharp and blunt fins, peaking at the location where the flow reattached. The highest value of heat transfer coefficient for the sharp fin was 2.5 times higher, compared to nearby undisturbed region values, and 2.0 times higher for the blunt fin, also compared to nearby undisturbed region values. Flaherty and Austin [44] investigated effects of concave geometry within a Mach 5.2 flow, produced in a shock tube, using two curved models with 16 and 25 degree turning angles, as well as a flat plate and a linear ramp for baseline comparisons. Concave wall geometries were of interest in hypersonic flight because they were employed in inward turning inlets. Of particular interest in the investigation were destabilizing mechanisms for concave surface boundary layers, including adverse pressure gradients, streamline curvature effects, and centrifugal instabilities. The investigators found significant signs of heat flux increases along the concave surfaces, which were attributed to the combined effects of surface curvature and adverse pressure gradient. Gaitonde [45] reviewed shockwave boundary layer interaction investigations, in regard to unsteadiness (particularly low frequency unsteadiness), heat transfer predictions, phenomena in complex shock interactions, and flow control techniques. Considered mostly were numerical studies, with very little comments or discussions provided in relation to experimental work. $\mathrm{He}$

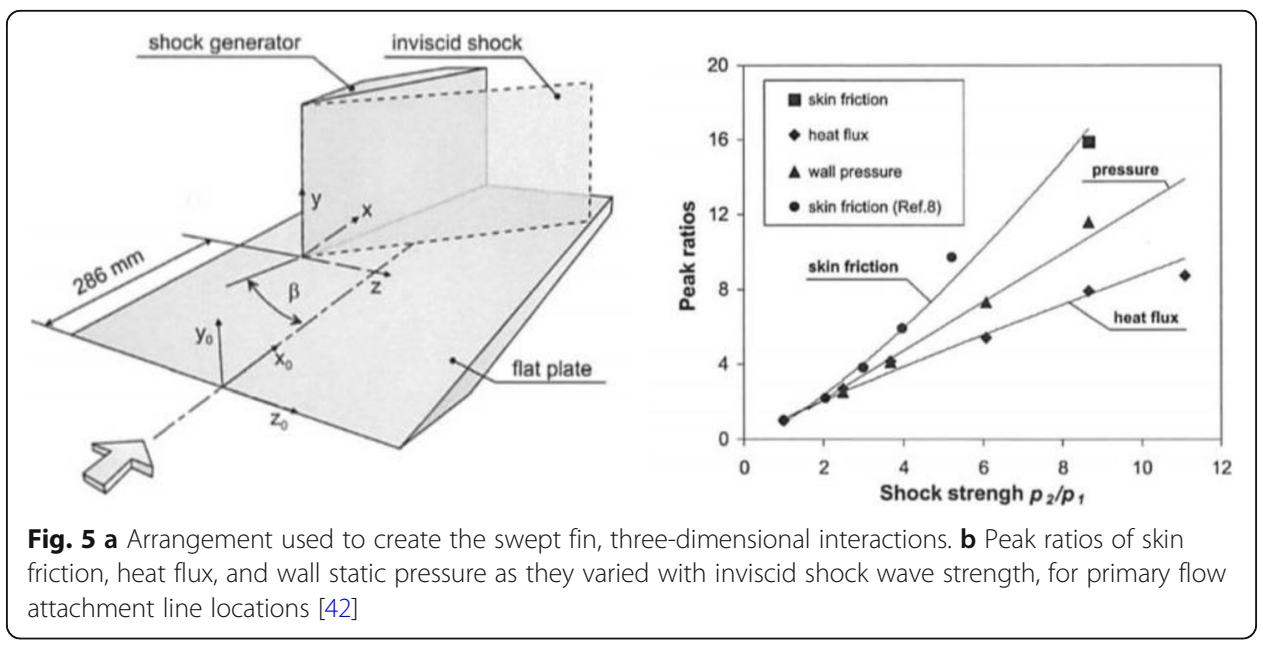


indicated that, until the 1990s, most numerical heat transfer work focused on turbulent boundary layer interactions. These data were generally used to advance twodimensional and three-dimensional modeling capabilities. Activities since that time have focused on improvement of databases related to hypersonic laminar interactions, especially in regard to development of DNS and LES models.

Investigations of heat transfer from shock wave interactions, as related to turbomachinery academic disciplines, addressed a variety of experimental configurations and conditions. Such shock waves are present within the turbines of high performance aero-engine gas turbines. They often develop both (i) at the trailing edges of stator vanes and rotor blades which operate with transonic flow, and (ii) within tip gap regions of unshrouded turbines.

In regard to (i), rotor blade passages of such engines contain considerable large-scale unsteadiness because of motion relative to stator vanes located upstream. With transonic flow, shock waves are generated at the trailing edges of upstream stator vanes (when exit Mach numbers range from 1.1 to 1.4), which then travel through rotor passages. According to Nix et al. [46], the resulting shock waves advect into the rotor blade passage, with repeated complex variations and changes as time progresses. At first, initial shock wave motion can be tangential to the rotor surface, followed by bifurcations and repeated reflections, including transient activity with shock waves which are temporarily normal to parts of the pressure surface, and temporarily tangent to suction surface locations. According to Abhari et al. [47], because many of the shock waves are reflected off of rotor blade surfaces as they are advected, as many as six shock waves may be moving through the rotor passage at any one time - some upstream, some downstream, some strengthening, some attenuating. As a result, flows near rotor surfaces are subject to large-scale static pressure pulsations from blade row motion, as well as to smaller-scale local static pressure variations, as different shock wave components are passing locally.

According to Johnson et al. [48], shock waves are the most important source of flow unsteadiness within transonic turbine components. Their contributions to the unsteadiness increase in importance as the stator vane exit Mach number increases. At higher turbine Mach numbers (for example, near 1.4 at the stator exit), perturbations to local heat transfer rates from shock waves may be as large as four times time-averaged values, with both positive and negative short-duration heat transfer pulses [48]. Results from Nix et al. [46], Johnson et al. [48], Abhari et al. [47], and Joe et al. [49] generally illustrate flow and thermal property changes both upstream and downstream of shock waves. Additional related studies are described by Doorly and Oldfield [50], Ashworth et al. [51], Guenette et al. [52], Rigby et al. [53], and Popp et al. [54].

In regard to (ii), for the past several decades, thermal-mechanical constraints on increasing the rotational speed of shrouded blades have driven many engine manufacturers to use unshrouded blades. However, unshrouded blades require a tip clearance to avoid striking the casing. The resulting over-tip leakage flow has high velocity and high temperature, leading to high local heat transfer rates and large material surface temperature gradients on the tip, as well as aerodynamic losses. At engine-scale conditions typical of a single-stage high-pressure aero-engine turbine, a large proportion of the tip flow is transonic. This means that shock waves form within the tip gap, creating large local pressure gradients, which significantly affect local boundary layer development along 
the tip. According to Zhang et al. $[55,56]$, important variations of surface heat transfer are present from a family of oblique shock waves, which are subject to repeated reflections. An example of results from those investigations is presented in Fig. 6. This figure shows virtual Schlieren visualizations of density gradient distributions (in gray scale) for four cut planes on the blade tip surface along the leakage flow streamlines direction. Included is the surface heat flux distribution on the blade tip surface by color scale. The locations of oblique shock waves within the tip gap are clearly visible within Fig. 6. Here, there are two main mechanisms that affect the local heat transfer coefficient on the tip. These are first shear stress, which is largely set by the boundary-layer thickness, and the second is turbulent mixing, which is affected by local streamwise pressure gradient. Underneath each oblique shock reflection, the boundary-layer experiences a large adverse pressure gradient, which leads to an increase in turbulence generation. In the reattachment region, after this separation region, heat transfer levels are high because the separation promotes turbulence production. Downstream of the reattachment region, flow is supersonic and accelerates rapidly thus causing a reduction in turbulence, which reduces the heat transfer. Thus, there is a rapid increase in surface heat transfer as the flow above moves across the shock wave. The result is a pattern of high and low tip surface heat transfer stripes, normal to the flow direction, which are due to rapid acceleration and deceleration, which occur prior to and across the shock wave reflections $[55,56]$.

Additional turbine blade tip investigations, which illustrated surface heat transfer and aerodynamic variations from shock wave effects, were numerous. Blade tip arrangements

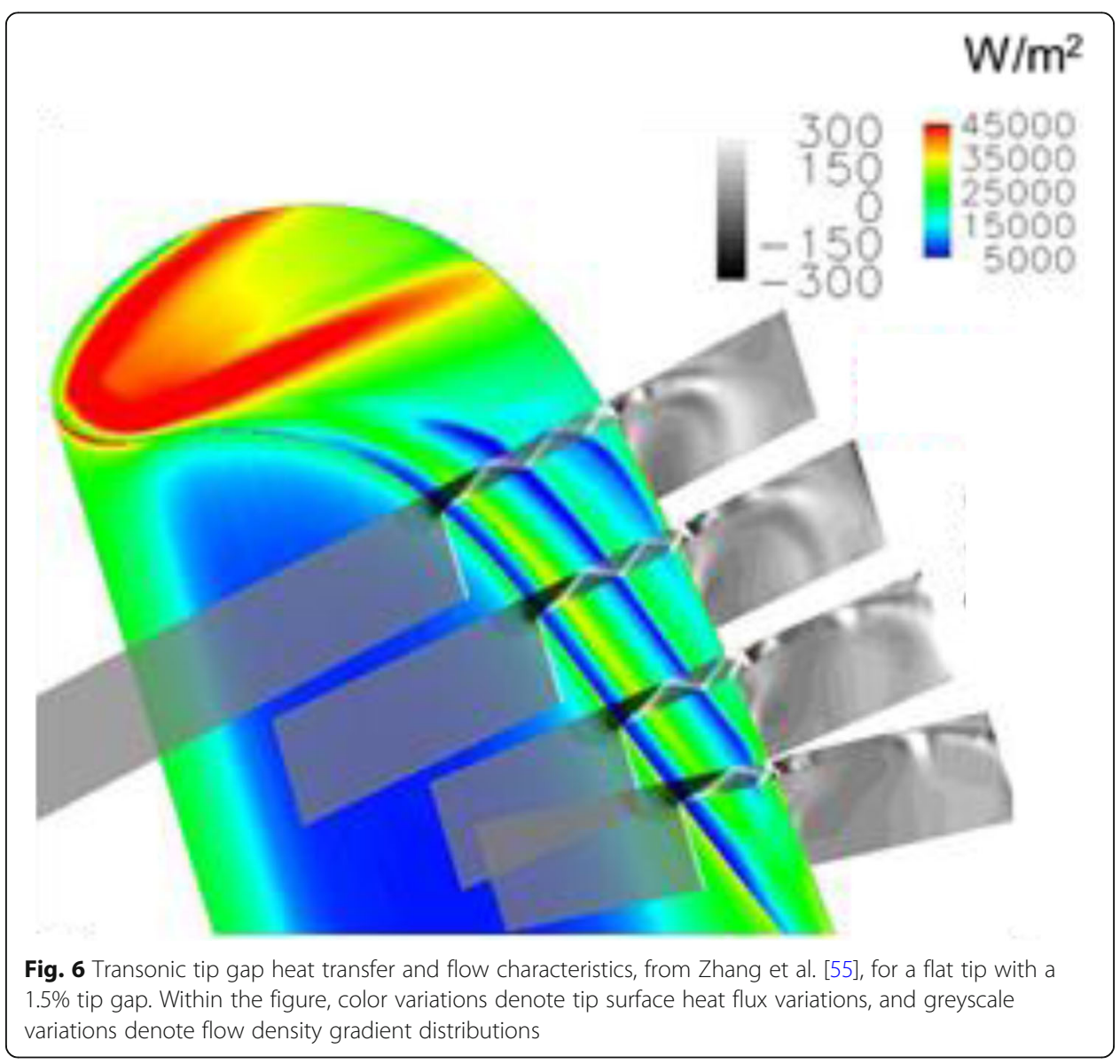


which were employed in these studies utilized squealer configurations [57-72], partial squealer configurations $[61,64,69]$, and winglet configurations [73, 74]. Smooth blade tips were employed by Thorpe et al. [75], Green et al. [59], Key and Arts [62], O'Dowd et al. [76, 77], Wheeler et al. [78], Zhang et al. [55, 56], Shyam et al. [79], Atkins et al. [80], Wheeler and Saleh [70], Anto et al. [81], Virdi et al. [68], Wheeler and Sandberg [82], Li et al. [65], Zhang et al. [83], Zhang and He [84], Wang et al. [69], Zhou [71], Jung et al. [61], Gao et al. [85], and Kim et al. [64]. Most of these investigations (which involved experimental measurements) employed annular or linear cascades with stationary blades. Annular arrangements with rotating turbine blades were utilized by Dunn and Haldeman [58], Didier et al. [86], Thorpe et al. [75], Green et al. [59], Key and Arts [62], Shyam et al. [79], and Atkins et al. [80].

\section{Shock wave interaction control investigations}

Considered in this section are recent investigations, which were focused on active and passive control of shock wave/boundary layer interactions. Discussed are investigations related to control of shock wave unsteadiness, control of shock wave-induced separations, and overall control of shock wave interactions. This subject area is an important one because of the connections between shock wave control technologies and requirements to reduce or minimize the adversarial effects of shock wave interactions as they affect performance characteristics associated with application environments.

Early research efforts with passive control methods utilized cavities and/or porous surfaces [87-92], ventilation [93], and "pressure plateaus" [94]. Early research efforts with active control methods employed wall jets [95], boundary layer bleeding [96], tangential blowing [97, 98], and wall suction [90, 92, 98].

In regard to more recent passive control method investigations, Qin et al. [99] investigated winglets with arrays of three-dimensional shock control bumps using numerical prediction techniques, along with an adjoint-based optimisation methodology. Results evidenced significant aerodynamic performance improvements, relative to baseline configurations, for a particular aircraft planform arrangement. Eliasson et al. [100] examined the effects of small cylinders, placed at different locations and in various patterns within a test section, as they perturbed converging cylindrical shock waves, as they were generated within an annular cross sectional shock tube. In another investigation, Eliasson et al. [101] employed experimental and numerical tools to address effects of reflector boundaries on strong, annular shock waves within a co-axial shock tube at Mach numbers from 2.3 to 3.6. According to these investigators, the form of the converging shock was initially governed by the shape of the reflector and the nonlinear interaction between the shape of the shock and velocity of shock propagation.

Babinsky et al. [102] utilized microramp sub-boundary-layer vortex generators for control of supersonic oblique shock-wave/boundary layer interactions, as applied to supersonic engine inlets. With an inlet Mach number of 2.5, the generators were employed to delay separation within reflected shock wave interactions. When applied to a separated oblique shock-wave/boundary-layer interaction, generated with a 7 degree angle wedge, the microramps were not able to completely eliminate flow separation, although they were shown to break up separated regions. Troia et al. [103] employed numerical RANS/ Large Eddy Simulations to also investigate the use of micro-ramps as a passive method of controlling normal shock/boundary layer 
interactions. Of particular interest were boundary layer separation zones, for external compression inlet applications. Each micro-ramp was placed upstream of different strength normal shock wave interaction zones, with flow Mach numbers as high as 1.8. According to these investigators, the micro-ramps were successful in reducing massive boundary layer separation, but at the expense of off-surface viscous free shear layer development. Throat total pressure recovery was improved over baseline arrangements (with no flow control), along with magnitudes of boundary layer shape factor. Bo et al. [104] investigated methods of shock wave interaction control, again using micro-ramps within experimental environments. These investigators indicated that effects of microramps could be significant, depending upon the spanwise locations of their influences within interaction regions. For some experimental conditions, separation regions were dampened as micro-ramps energized portions of the incoming boundary layer flow. Zhou et al. [105] investigated porous slots and bumps, with variations of porosity distribution, hole diameter, cavity depth, and porosity direction, for drag reduction of a supercritical wing. Wind tunnel test results for angle of attack of 2 degrees showed that the porous configuration with $6.21 \%$ porosity resulted in a measurable drag reduction and lift-drag ratio increase, whereas the small bump configuration resulted in even higher magnitudes of drag reduction and lift-drag ratio.

In regard to more recent active control method investigations, Merriman et al. [106] employed non-equilibrium and weakly-ionized plasmas in cold supersonic gas flows for shock wave control. Experiments were performed with steady-state conditions at low temperatures, with a Mach number of 2. According to the investigators, the use of discharge increased the shock wave angle by 14 degrees, from 99 to 113 degrees, which corresponded to a Mach number reduction from 2.0 to 1.8. Because the flow residence time in the test section was of the order of $10 \mu \mathrm{s}$, the mechanism of shock weakening was believed to be due to heating of the boundary layers and the nozzle walls by the discharge. Anderson et al. [107, 108] investigated micro-array actuation for controlling the shock wave turbulent boundary layer interactions within supersonic inlets at a free stream Mach number of 2.0. The micro-actuator arrays had different heights, relative to undisturbed supersonic boundary layer thickness, and were in the form of standard micro-vanes, tapered micro-vanes, and standard micro-ramp arrays. The overall objective was alteration of the properties of the supersonic boundary layer using a collection of counter-rotating micro-vortices in the near wall region.

Narayanaswamy et al. [109], Webb et al. [110], and Greene et al. [111] employed various types of plasma actuators to control different shock wave phenomena. Of these investigations, Narayanaswamy et al. [109] used a pulsed-plasma jet actuator to control unsteady motion of the separation zone downstream of a shock wave/boundary layer interaction formed by a compression ramp with a flow Mach number of 3. The most significant changes were achieved when the actuator was placed upstream of the separation zone. With this arrangement, separation unsteadiness was locked to the pulsing frequency of the actuator, with an amplitude of approximately one boundary layer thickness. Webb et al. [110] also attempted separation control using localized arc filament plasma actuators (LAFPAs) within a Mach 2.3 flow. Control of interactions was evidenced by displacement of the reflected shock wave and significant portions of the interaction region upstream by approximately one boundary layer thickness. According to these researchers, local boundary layer modifications occurred because of heat 
addition by the actuators, in spite of extremely small actuator power input. Greene et al. [111] employed pulsed plasma jets (or spark jets) to reduce the separation, induced by shock wave-boundary layer interactions generated by a 20 degree compression ramp, within a flow with a Mach number of 3. Results showed that plasma jets pitched at an appropriate inclination angle (relative to the test surface), and pulsed at an appropriate frequency, reduced the distance between the separation line and the compression ramp corner by up to $40 \%$, along with an increase of momentum thickness of the downstream reattached boundary layer.

Pasquariello et al. [112] investigated methods of shock wave interaction control using separation zone suction within numerically predicted environments. These investigators showed a shift of high-energy, low-frequency energy to higher frequencies, with a concomitant reduction of overall energy levels, provided suction was applied within the downstream portions of separated zones. Liu et al. [113] investigated the effects of steady and pulsed arc discharge arrangements, where the latter were employed at frequencies from 5 to $50 \mathrm{kHz}$, for control of an oblique shock wave, formed using a compression ramp with an angle of 7 degrees relative to the wind tunnel test surface. The experimental study was undertaken using a supersonic wind tunnel with a maximum flow Mach number of 2.5. Results showed that the steady discharge arcs acted like a uniformly distributed conductor. As the arc length was increased, the arc power increased, and the weakening effect on the shock was enhanced. Overall, the weakening effect of the steady arcs on the shock was more effective with shock strength reduced by $4 \%$. In contrast, reductions with pulsed arrangements were only as large as approximately $0.35 \%$.

\section{Summary and conclusions}

The present survey provides an overview of the present state of knowledge on such effects and interactions, including discussions of: (i) general features of shock wave interactions, (ii) test section configurations for investigation of shock wave boundary layer interactions, (iii) origins and sources of unsteadiness associated with the interaction region, (iv) interactions which included thermal transport and convective heat transfer, and (v) shock wave interaction control investigations.

Determination of the origins and sources of low-frequency, large-scale shock wave unsteadiness has been especially vexing for investigators. In order to develop some consensus and to reconcile a variety of different perspectives, Clemens and Narayanaswamy [3] provided an excellent survey of the state-of-the-art, as of 2014. According to these individuals, both upstream and downstream mechanisms were present within all interactions, such that the downstream mechanism dominated for strongly separated flows, and combined upstream and downstream mechanisms dominated for weakly separated flows. As such, the relative importance and effects of upstream and dowsntream mechanisms changed as separation strength varied. In particular, the degree of influence of the upstream boundary layer diminished as separation strength and scale increased. Additional details regarding flow physics of shock wave boundary layer interactions, including generation of the separation region from strong pressure gradients, and overall structure of different types of interactions, were provided by Babinsky and Harvey [114]. Future research is expected to show that the physical mechanisms responsible for shock wave unsteadiness are even more complex than revealed by past investigations. 
In regard to shock wave investigations, where heat transfer and thermal transport were important, much practical information is available in regard to turbomachinery component environments and conditions, with only limited practical and design information available related to aerospace and aeronautical component environments and conditions. Important deficits in understanding of fundamental thermal transport mechanisms, as related to shock waves, are present for both academic disciplines. Needed are new data which connect unsteady shock wave characteristics to local instantaneous and time-averaged turbulent transport characteristics, and to local, instantaneous and time-averaged surface heat transfer distributions, especially for direct application to aerospace components. One motivation for improved understanding of interactions and the associated unsteadiness is improved interaction control strategies. However, no single shock wave control strategy is available, which may be successfully applied to different shock wave arrangements, over a wide range of Mach numbers. Efforts to develop effective shock wave control methods have been underway as long as shock waves have been investigated, with surveys of related technologies provided by Pearcey [115], Delery [116], Fulker [117], Stanewsky [118], and others. It is anticipated that innovative and unique control techniques and strategies will be developed in the future, which will be applicable over a wider range of experimental conditions, relative to previously developed approaches.

\section{Nomenclature}

$C_{y 1 y 2}$ Magnitude squared coherence

$\delta_{o}$ Boundary layer thickness

$\beta$ Shock generator plate angle, relative to freestream flow direction

$f$ Frequency

$L_{i}$ Streamwise length of intermittent flow region

$L_{\text {sep }}$ Streamwise length of flow separation region

$M_{\infty}$ Freestream flow Mach number

$p_{1}$ Static pressure upstream of shock wave

$p_{2}$ Static pressure downstream of shock wave

$x$ Streamwise coordinate

$x_{0}$ Streamwise coordinate, measured from test surface leading edge

$x^{*}$ Normalized streamwise coordinate

$y$ Normal coordinate, measured from test surface

$y_{0}$ Normal coordinate, measured from test surface leading edge

$y^{*}$ Normalized normal coordinate

$z$ Spanwise coordinate, measured from test surface

$z_{0}$ Spanwise coordinate, measured from test surface leading edge

\section{Acknowledgements}

The following individuals are acknowledged for their assistance with laboratory development, laboratory testing, laboratory instrumentation and apparatus, and/or data analysis: Tony Hall, David Lineberry, Andrew Miller, Robert Pertrimoulx, Daniel Corey, Soo Rhee, Conner Gisburne, Kaylee Hall, Sarah Stearman, Benjamin Shea, Benjamin Lund, Connor Pierce, Patrick McInturff, and Warren Buzzard. 


\section{Funding}

The Alabama Innovation Fund (Contract ID No. 61070000002), the University of Alabama Endowment Fund, and the Office of the Vice President for Research and Economic Development of the University of Alabama in Huntsville are acknowledged for financial support for the research which is reported within the present paper.

\section{Availability of data and materials}

Additional information on data analysis procedures can be obtained from the corresponding author.

\section{Competing interests}

The authors declare that they have no competing interests.

Received: 9 September 2019 Accepted: 9 January 2020

Published online: 07 February 2020

\section{References}

1. Dussauge JP, Piponniau S (2008) Shock/boundary-layer interactions: possible sources of unsteadiness. J Fluids Struct 24: 1166-1175

2. Gonsalez JC, Dolling DS (1993) Correlation of interaction sweepback effects on the dynamics of shock-induced turbulent separation. 31st AIAA Aerosp Sci meeting and exhibit, paper 1993-0776, Reno

3. Clemens NT, Narayanaswamy V (2014) Low-frequency unsteadiness of shock wave turbulent boundary layer interactions. Ann Rev Fluid Mech 46:469-492

4. Grilli M, Schmid PJ, Hickel S, Adams NA (2012) Analysis of unsteady behavior in shockwave turbulent boundary layer interaction. J Fluid Mech 700:16-28

5. Dolling DS, Murphy MT (1983) Unsteadiness of the separation shock wave structure in a supersonic compression ramp flow field. AIAA J 21:1628-1634

6. Humble RA, Elsinga GE, Scarano F, van Oudheusden BW (2009) Three-dimensional instantaneous structure of a shock wave/turbulent boundary layer interaction. J Fluid Mech 622:33-62

7. Ganapathisubramani B, Clemens NT, Dolling DS (2007) Effects of upstream boundary layer on the unsteadiness of shock induced separation. J Fluid Mech 585:369-394

8. Ganapathisubramani B, Clemens NT, Dolling DS (2009) Low frequency dynamics of shock induced separation in a compression ramp interaction. J Fluid Mech 636:397-436

9. Piponniau S, Dussauge JP, Debieve JF, Dupont P (2009) A simple model for low-frequency unsteadiness in shockinduced separation. J Fluid Mech 629:87-108

10. Touber E, Sandham ND (2011) Low-order stochastic modelling of low frequency motions in reflected shock-wave/ boundary-layer interactions. J Fluid Mech 671:417-465

11. Wu M, Martín MP (2008) Analysis of shock motion in shockwave and turbulent boundary layer interaction using direct numerical simulation data. J Fluid Mech 594:71-83

12. Pirozzoli S, Larsson J, Nichols JW, Bernardini M, Mogan BE, Lele SK (2010) Analysis of unsteady effects in shock/boundary layer interactions. Proceedings of the Summer Program 2010. Center for Turbulence Research, Stanford University, Stanford, pp 153-164

13. Sajben M, Kroutil JC (1981) Effects of initial boundary layer thickness on transonic diffuser flows. AIAA J 19:1386-1393

14. Bogar TJ, Sajben M, Kroutil JC (1983) Characteristic frequencies of transonic diffuser flow oscillations. AIAA J 21:12321240

15. Robinet JC, Casalis G (1999) Shock oscillations in diffuser modeled by a selective noise amplification. AIAA J 37:453-459

16. Handa T, Masudo M, Matsuo K (2003) Mechanism of shock wave oscillation in transonic diffusers. AIAA J 41:64-70

17. Edwards JA, Squire LC (1993) An experimental study of the interaction of an unsteady shock with a turbulent boundary layer at Mach numbers of 1.3 and 1.5. Aero J 97:337-348

18. Ott P, Bolcs A, Frannson TH (1995) Experimental and numerical study of the time-dependent pressure response of a shock wave oscillating in a nozzle. J Turbomach 117:106-114

19. Bur R, Benay R, Galli A, Berthouze P (2006) Experimental and numerical study of forced shock wave oscillations in a transonic channel. Aerospace Sci Tech 10:265-278

20. Bruce PJK, Babinsky H (2008) Unsteady shock wave dynamics. J Fluid Mech 603:463-473

21. Threadgill J, Bruce PJK (2014) Study of transonic shock wave/boundary layer interactions subject to unsteady forcing. AIAA SciTech, National Harbor

22. Doerffer P, Szulc O, Magagnato F (2005) Unsteady shock wave-turbulent boundary layer interaction in the Laval nozzle. Task Quart 9:115-132

23. Ogawa H, Babinsky H (2006) Wind-tunnel setup for investigations of normal shock wave/boundary-layer interaction control. AIAA J 44:2803-2805

24. Ligrani PM, Marko SR (2020) Parametric study of wind tunnel test section configurations for stabilizing normal shock wave structure. Shock Waves 30(1):77-90

25. Marko SR, Ligrani PM (2019) Analysis of shock wave unsteadiness using space and time correlations applied to shadowgraph flow visualization data. Adv. Aerodyn. 1, 2 https://doi.org/10.1186/s42774-019-0002-y

26. Zheltovodov AA, Trofimov VM, Schülein E, Yakovlev VN (1990) An experimental documentation of supersonic turbulent flows in the vicinity of forward- and backward-facing ramps. Tech Rep 2030, Inst Theor Appl Mech, USSR Acad Sci, Novosibirsk

27. Priebe S, Martín M (2012) Low-frequency unsteadiness in shock wave-turbulent boundary layer interaction. J Fluid Mech 699:1-49

28. Burton D, Babinsky H (2012) Corner separation effects for normal shock wave/turbulent boundary layer interactions in rectangular channels. J Fluid Mech 707:287-306

29. Babinsky H, Oorebeek J, Cottingham T (2013) Corner effects in reflecting oblique shock-wave/boundary-layer interactions. 51st AIAA Aerosp Sci Mtg, Grapevine 
30. Wang B, Sandham N, Hu Z, Liu W (2015) Numerical study of oblique shock-wave/boundary-layer interaction considering sidewall effects. J Fluid Mech 767:526-561

31. Law CH (1975) 3-D shock wave-turbulent boundary layer interactions at Mach 6. US Air Force Aero Res Labs, Dayton

32. Christophel RG, Rockwell WA, Neumann RD (1975) Tabulated Mach 6 3-D shock wave-turbulent boundary layer interaction heat transfer data (supplement). Air force flight dynamics lab, Dayton

33. Oskam B, Vas IE, Bogdonoff SM (1976) Oblique shock wave/turbulent boundary layer interactions in three dimensions at Mach 3, part 2. Air Force Flight Dyn Lab, Dayton

34. Holden MS (1984) Experimental studies of quasi-two-dimensional and three-dimensional viscous interaction regions induced by skewed-shock and swept-shock boundary layer interaction. 17th AlAA Fluid Dynamics, Plasma Dynamics, and Lasers Conference, Snowmass

35. Inger GR, Lynch FT, Fancher MF (1985) Theoretical and experimental study of nonadiabatic transonic shock/boundarylayer interaction. AIAA J 23:1476-1482

36. Neumann RD, Hayes JR (1986) Introduction to aerodynamic heating analysis of supersonic missiles. Tactical Missile Aerodynamics, Prog Astro Aero, AIAA, New York, USA 104:421-479

37. Hayashi M, Sakurai A, Aso S (1987) Measurements of heat-transfer coefficients in the interaction regions between oblique shock waves and turbulent boundary layers with a multi-layered thin film heat transfer gage. Jap Soc Aero Space Sci J 30:102-110

38. Hayashi M, Aso S, Tan A (1989) Fluctuation of heat transfer in shock wave/turbulent boundary-layer interaction. AlAA J 27:399-404

39. Rodi PE, Dolling DS (1992) An experimental/computational study of sharp fin induced shock wave/turbulent boundary layer interactions at Mach 5: experimental results. 30th AIAA Aero Sci Mtg, Reno

40. Lee Y, Settles GS, Horstman CC (1992) Heat transfer measurements and CFD comparison of swept shock wave/ boundary-layer interactions. 28th AIAA Joint Propulsion Conf, Nashville

41. Inger GR (1998) Theory of local heat transfer in shock/laminar boundary-layer interactions. J Thermo Heat Trans 12:336-342

42. Schülein E (2006) Skin friction and heat flux measurements in shock/boundary layer interaction flows. AIAA J 44:17321741

43. Song JW, Yu MS, Cho HH (2007) Heat transfer near sharp and blunt fins protruded in a supersonic flow. In: Coll Tech Papers, vol 1. 39th AIAA Thermophysics Conf, Miami, pp 601-608

44. Flaherty W, Austin J (2010) Effect of concave wall geometry on heat transfer in hypersonic boundary layers. 40th AIAA fluid Dyn Conf, Chicago

45. Gaitonde DV (2013) Progress in shock wave/boundary layer interactions. 43rd AlAA fluid Dyn Conf, Progress in Aero Sci 72:80-99

46. Nix AC, Diller TE, Ng WF, Schetz JA (1997) Experimental evaluation of heat transfer effects of shock waves on transonic turbine blades. ASME Paper No. 97-WA/HT-1, ASME International Mechanical Engineering Congress and Exhibition, Dallas

47. Abhari RS, Guenette GR, Epstein AH, Giles MB (1992) Comparison of time-resolved turbine rotor blade heat transfer measurements and numerical calculations. ASME Transactions-Journal of Turbomachinery 114:818-827

48. Johnson AB, Rigby MJ, Oldfield MLG, Ainsworth RW, Oliver MJ (1989) Surface heat transfer fluctuations on a turbine rotor blade due to upstream shock wave passing. J Turbomach 111:105-115

49. Joe CR, Montesdeoca XA, Soechting FO, MacArthur CD, Meininger M (1998) High pressure turbine vane annular cascade heat flux and aerodynamic measurements with comparisons to predictions. ASME Paper No. 98-GT-430, International Gas Turbine and Aeroengine Congress and Exhibition, Stockholm

50. Doorly DJ, Oldfield MLG (1985) Simulation of the effects of shock wave passing on a turbine rotor blade. ASME J Eng Gas Turbines Power 107:998-1006

51. Ashworth DA, LaGraff JE, Schultz DL, Grindrod KJ (1985) Unsteady aerodynamic and heat transfer processes in a transonic turbine stage. J Eng Gas Turbines Power 107:1022-1030

52. Guenette GR, Epstein AH, Giles MB, Haimes R, Norton RJG (1989) Fully scaled transonic turbine rotor heat transfer measurements. J Turbomach 111:1-7

53. Rigby MJ, Johnson AB, Oldfield MLG (1990) Gas turbine rotor blade film cooling with and without simulated NGV shock waves and wakes. ASME International Gas Turbine and Aeroengine Congress and Exposition, Vol 4: Heat Transfer; Electric Power; Industrial and Cogeneration, Brussels

54. Popp O, Smith DE, Bubb JV, Grabowski HC III, Diller TE, Schetz JA, Ng WF (2000) Investigation of heat transfer in a film cooled transonic turbine cascade: part II - unsteady heat transfer. ASME Turbo Expo 2000: Power for land, sea, and air, Vol 3: Heat Transfer; Electric Power; Industrial and Cogeneration, Munich

55. Zhang Q, O'Dowd DO, He L, Wheeler APS, Ligrani PM, Cheong BCY (2011a) Overtip shock wave structure and its impact on turbine blade tip heat transfer. J Turbomach 133:041001

56. Zhang Q, O'Dowd DO, He L, Oldfield MLG, Ligrani PM (2011b) Transonic turbine blade tip aerothermal performance with different tip gaps_-part 1: tip heat transfer. ASME Transactions, J Turbomachinery 133:041027

57. Arisi A, Phillips J, Ng WF, Moon HK, Zhang L (2016) An experimental and numerical study on the aerothermal characteristics of a ribbed transonic squealer-tip turbine blade with purge flow. J Turbomach 138:101007

58. Dunn MG, Haldeman CW (2000) Time-averaged heat flux for a recessed tip, lip, and platform of a transonic turbine blade. J Turbomach 122:692-698

59. Green BR, Barter JW, Haldeman CW, Dunn MG (2005) Averaged and time-dependent aerodynamics of a high pressure turbine blade tip cavity and stationary shroud: comparison of computational and experimental results. J Turbomach 127:736-746

60. Hofer T, Arts T (2009) Aerodynamic investigation of the tip leakage flow for blades with different tip squealer geometries at transonic conditions. ASME Turbo Exp: Power for Land, Sea, and Air, Turbomachinery, Parts A and B 7 : 1051-1061, Orlando

61. Jung J, Kwon O, Son C (2016) An investigation on aerodynamics loss mechanism of squealer tips of a high pressure turbine blade using URANS. ASME TurboExpo: TurboMachinery Technical Conference and Exposition, Seoul

62. Key NL, Arts T (2006) Comparison of turbine tip leakage flow for flat tip and squealer tip geometries at high-speed conditions. J Turbomach 128:213-220 
63. Kim J, Kang YS, Kim D, Lee J, Cha BJ, Cho J (2016) Optimization of a high pressure turbine blade tip cavity with conjugate heat transfer analysis. J Mech Sci Tech 30:5529-5538

64. Kim JH, Lee SY, Chung JT (2019) Numerical analysis of the aerodynamic performance \& heat transfer of a transonic turbine with a partial squealer tip. Appl Therm Eng 152:878-889

65. Li W, Jiang H, Zhang Q, Lee SW (2014) Squealer tip leakage flow characteristics in transonic condition. J Eng Gas Turbines Power 136:042601/1-042601/7

66. Ma H, Zhang Q, He L, Wang Z, Wang L (2017a) Cooling injection effect on a transonic squealer tip-part l: experimental heat transfer results and CFD validation. J Eng Gas Turbines Power 139:052506

67. Ma H, Zhang Q, He L, Wang Z, Wang L (2017b) Cooling injection effect on a transonic squealer tip-part Il: analysis of aerothermal interaction physics. J Eng Gas Turbines Power 139:052507

68. Virdi AS, Zhang Q, He L, Li HD, Hunsley R (2013) Aerothermal performance of shroudless turbine blade tips with effects of relative casing motion. ASME Turbine Blade Symposium Paper NoTBTS2013-2021

69. Wang Z, Zhang Q, Liu Y, He L (2015) Impact of cooling injection on the transonic over-tip leakage flow and squealer aerothermal design optimization. J Eng Gas Turbines Power 137:062603

70. Wheeler AP, Saleh Z (2013) Effect of cooling injection on transonic tip flows. J Propuls Power 29:1374-1381

71. Zhou C (2015) Thermal performance of transonic cooled tips in a turbine cascade. J Propulsion and Power 31:1268-1280

72. Zhu D, Lu S, Ma H, Zhang Q, Teng J (2017) Rotating effect on transonic squealer tip cooling performance. ASME Turbo Expo, Turbomachinery Technical Conference and Exposition, Volume 5A: Heat Transfer, Charlotte

73. O'Dowd D, Zhang Q, He L, Oldfield MLG, Ligrani PM, Cheong BCY, Tibbott I (2011) Aerothermal performance of a winglet at engine representative Mach and Reynolds numbers. J Turbomach 133:041026

74. Zhong F, Zhou C, Ma H, Zhang Q (2017) Heat transfer of winglet tips in a transonic turbine cascade. J Turbomach 139 012605

75. Thorpe SJ, Yoshino S, Thomas GA, Ainsworth RW, Harvey NW (2005) Blade-tip heat transfer in a transonic turbine. Proc Inst Mech Eng A J Power 219:421-430

76. O'Dowd DO, Zhang Q, He L, Ligrani PM, Friedrichs S (2010a) Comparison of heat transfer measurements on a transonic turbine blade tip. ASME J Turbomach 133:021028

77. O'Dowd DO, Zhang Q, Usandizaga I, He L, Ligrani PM (2010b) Transonic turbine blade tip aero-thermal performance with different tip gaps: part I-tip heat transfer. J Turbomach 133:041027

78. Wheeler APS, Atkins NR, He L (2011) Turbine blade tip heat transfer in low speed and high speed flows. J Turbomach 133:041025

79. Shyam V, Ameri A, Chen J-P (2011) Analysis of unsteady tip and endwall heat transfer in a highly loaded transonic turbine stage. J Turbomach 134:041022

80. Atkins NR, Thorpe SJ, Ainsworth RW (2012) Unsteady effects on transonic turbine blade-tip heat transfer. J Turbomach 134:061002/1-061002/11

81. Anto K, Xue S, Ng W, Zhang L, Moon H (2013) Effects of tip clearance gap and exit Mach number on turbine blade tip and near-tip heat transfer. ASME Turbo expo, paper no GT2013-94345

82. Wheeler APS, Sandberg RD (2013) Direct numerical simulations of a transonic tip flow with free-stream disturbances. ASME paper TBTS2013-2037

83. Zhang Q, He L, Rawlinson A (2014) Effects of inlet turbulence and end-wall boundary layer on aerothermal performance of a transonic turbine blade tip. J Eng Gas Turbines and Power 136:052603-052607

84. Zhang Q, He L (2014) Impact of wall temperature on turbine blade tip aerothermal performance. J Eng Gas Turbines Power 136:052602

85. Gao J, Zheng Q, Dong P, Fu W (2017) Effects of flow incidence on aerothermal performance of transonic blade tip clearance flows. Energy 139:196-209

86. Didier F, Denos R, Arts T (2002) Unsteady rotor heat transfer in a transonic turbine stage. J Turbomach 123:81-89

87. Ashill P, Fulkner J, Shires A (1992) A novel technique for controlling shock strength of laminar-flow aerofoil sections. Proceedings of the 1st European forum on laminar flow technology, Hamburg, DGLR Bericht 6:175-183

88. Bahi L, Ross J, Nagamatsu H (1983) Passive shock wave/boundary layer control for transonic airfoil drag reduction. 21st AIAA Aero Sci Mtg, Reno

89. Bur R (1992) Passive control of a shock wave/turbulent boundary layer interaction in a transonic flow. Aerospace Research (La Recherche Aérospatiale) 6:11-30

90. Bur R, Corbel B, Délery J (1998) Study of passive control in a transonic shock wave/boundary-layer interaction. AIAA J 36:394-400

91. Nagamatsu HT, Ficarra RV, Dyer R (1985) Supercritical aerofoil drag reduction by passive shock wave/boundary layer control in the Mach number range. 23rd AIAA Aero Sci Mtg, Reno, pp 75-90

92. Raghunathan S, Mcllwain ST (1990) Further investigations of transonic shock wave/boundary-layer interaction with passive control. J Aircraft 27:60-65

93. Bohning R, Jungbluth H (1989) Turbulent shock - boundary-layer interaction with control theory and experiment. IUTAM, Symposium Transsonicum III, Springer, Berlin, Heidelberg, pp 389-398

94. Squire LC, Yeung AFK, Faucher X (1997) An investigation of passive control applied to swept shock-wave/boundarylayer interactions. AIAA J 56:135-150

95. Peake DJ (1966) The use of air injection to prevent separation of turbulent boundary layer in supersonic flow. ARC CP 890

96. Fukuda MK, Hingst WR, Reshotko E (1975) Control of shock wave-boundary layer interactions by bleed in supersonic mixed compression inlets. 11th AIAA Propulsion Conf, Anaheim

97. Schwendemann MF, Sanders BW (1982) Tangential blowing for control of strong normal shock-boundary layer interactions on inlet ramps. 18th AIAA Joint Propulsion Conf, Cleveland

98. Viswanath PR (1988) Shock-wave-turbulent-boundary-layer interaction and its control: a survey of recent developments. Sadhana 12:45-104

99. Qin N, Wong WS, Le Moigne A (2006) Adjoint-based optimisation of a blended wing body aircraft with shock control bumps. AIAA Aerosp Sci Meeting 111:165-174 
100. Eliasson V, Apazidis N, Tillmark N (2007) Controlling the form of strong converging shocks by means of disturbances. Shock Waves 17:29-42

101. Eliasson V, Apazidis N, Tillmark N, Lesser MB (2006) Focusing of strong shocks in an annular shock tube. Shock Waves 15:205-217

102. Babinsky H, Li Y, Pitt Ford CW (2009) Microramp control of supersonic oblique shock-wave/boundary-layer interactions. AIAA J 47:668-675

103. Troia T, Patel A, Crouse D, Hall G (2011) Passive device flow control for normal shock/boundary layer interactions in external compression inlets. 41st AIAA Fluid Dynamics Conference and Exhibit, Honolulu

104. Bo W, Weidong L, Yuxin Z, Xiaoquiang F, Chao W (2012) Experimental investigation of the micro-ramp based shock wave and turbulent boundary layer interaction control. Phys Fluids 24:055110

105. Zhou L, Chen D, Tao Y, Liu G, Song S, Zhong S (2017) Passive shock wave/boundary layer control of wing at transonic speeds. Theo App Mech Letters 7:325-330

106. Merriman S, Ploenjes E, Palm P, Adamovich I (2001) Shock wave control by nonequilibrium plasmas in cold supersonic gas flows. AlAA J 39:1547-1552

107. Anderson BH, Tinapple J, Surber L (2006a) Optimal control of shock wave turbulent boundary layer interactions using micro-array actuation. 3rd AIAA flow control conference, San Francisco

108. Anderson BH, Tinapple J, Surber L (2006b) Optimal micro-array actuation control for shock wave boundary layer interactions in supersonic inlets. Proposed NASA TM 214373

109. Narayanaswamy V, Raja L, Clemens N (2012) Control of unsteadiness of a shock wave/turbulent boundary layer interaction by using a pulsed-plasma-jet actuator. Phys Fluids 24:076101

110. Webb N, Clifford C, Samimy M (2013) Control of oblique shock wave/boundary layer interactions using plasma actuators. Exp Fluids 54:1545

111. Greene BR, Clemens NT, Magari P, Micka D (2015) Control of mean separation in shock boundary layer interaction using pulsed plasma jets. Shock Waves 25:495-505

112. Pasquariello V, Grilli M, Hickel S, Adams NA (2014) Large-eddy simulation of passive shock-wave/boundary-layer interaction control. Intern J Heat Fluid Flow 49:116-127

113. Liu F, Yan H, Zhan W, Xue Y (2019) Effects of steady and pulsed discharge arcs on shock wave control in Mach 2.5 flow. Aero Sci Tech 93:105330

114. Babinsky H, Harvey JK (2011) Shock wave - boundary-layer interactions. Cambridge University Press, Cambridge

115. Pearcey HH (1961) Boundary layer and flow control. Pergamon Press Inc., New York

116. Delery JM (1985) Shock wave/turbulent boundary layer interaction and its control. Prog Aero Sci 22:209-280

117. Fulker JL (1999) The euroshock programme (a european programme on active and passive control of shock waves). 17th AIAA Applied Aerodynamics Conference, Norfolk

118. Stanewsky E (2002) Drag reduction by shock and boundary layer control. Springer-Verlag, New York

\section{Publisher's Note}

Springer Nature remains neutral with regard to jurisdictional claims in published maps and institutional affiliations.

\section{Submit your manuscript to a SpringerOpen ${ }^{\circ}$ journal and benefit from:}

- Convenient online submission

Rigorous peer review

- Open access: articles freely available online

- High visibility within the field

- Retaining the copyright to your article

Submit your next manuscript at $\boldsymbol{\nabla}$ springeropen.com 